September 1999 • NREL/CP-520-26904

\title{
An Overview of Thermophotovoltaic Generation of Electricity
}

Timothy J. Coutts

Presented at the $11^{\text {th }}$ International Photovoltaics Science and Engineering Conference (PVSEC-11) Sapporo, Japan September 20-24, 1999
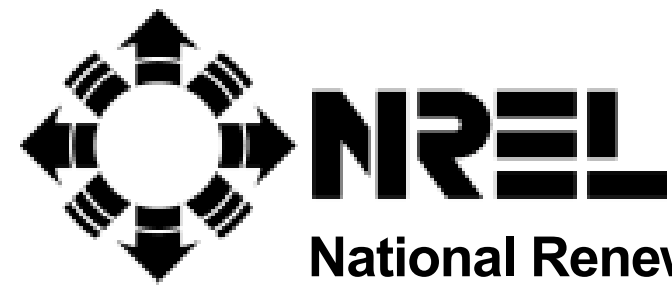

National Renewable Energy Laboratory

1617 Cole Boulevard Golden, Colorado 80401-3393

NREL is a U.S. Department of Energy Laboratory Operated by Midwest Research Institute $\bullet$ Battelle $\bullet$ Bechtel Contract No. DE-AC36-98-G010337 


\section{NOTICE}

This report was prepared as an account of work sponsored by an agency of the United States government. Neither the United States government nor any agency thereof, nor any of their employees, makes any warranty, express or implied, or assumes any legal liability or responsibility for the accuracy, completeness, or usefulness of any information, apparatus, product, or process disclosed, or represents that its use would not infringe privately owned rights. Reference herein to any specific commercial product, process, or service by trade name, trademark, manufacturer, or otherwise does not necessarily constitute or imply its endorsement, recommendation, or favoring by the United States government or any agency thereof. The views and opinions of authors expressed herein do not necessarily state or reflect those of the United States government or any agency thereof.

Available to DOE and DOE contractors from:

Office of Scientific and Technical Information (OSTI)

P.O. Box 62

Oak Ridge, TN 37831

Prices available by calling 423-576-8401

Available to the public from:

National Technical Information Service (NTIS)

U.S. Department of Commerce

5285 Port Royal Road

Springfield, VA 22161

$703-605-6000$ or $800-553-6847$

or

DOE Information Bridge

http://www.doe.gov/bridge/home.html

Printed on paper containing at least $50 \%$ wastepaper, including $20 \%$ postconsumer waste 


\title{
An Overview of Thermophotovoltaic Generation of Electricity
}

\author{
Timothy J. Coutts
}

\author{
National Renewable Energy Laboratory \\ Golden CO 80401, USA
}

\begin{abstract}
This paper provides an overview of the developments in thermophotovoltaic (TPV) generation of electricity that have occurred relatively recently_-from about 1994 to October 1998. The components considered are the semiconductor converter; the radiator; and the means of recirculating unusable, long-wavelength photons. A short account of the functions and performance of each of these components is given. Also discussed are operational systems and progress in modeling TPV systems.
\end{abstract}

\section{Introduction}

The origins of TPV date back to the early 1960 s, but it is only in relatively recent years that it has shown real promise. Incident and output power densities are much larger than flat-plate PV modules because of geometric considerations. The output power densities from the cells may eventually be as large as 5 watts $\mathrm{cm}^{-2}$, i.e., 50 times that of a flat-plate PV system, assuming the semiconductor converters work as efficiently as solar cells. Indeed, researchers have already demonstrated cell outputs of about 1 watt $\mathrm{cm}^{-2}$. The sun radiates mainly in the visible range of wavelengths, whereas a TPV radiator emits mainly in the near-infrared range. This demands semiconductor bandgaps of $0.4-0.7 \mathrm{eV}$ for efficient conversion. TPV development has been able to exploit the extraordinary progress made in the fields of III-V semiconductors and highefficiency solar cells.

Potential attractions of TPV include: high power density, fuel versatility, portability, silent operation, operation that is independent of the sun, and low maintenance. Possible applications include: stand-alone domestic gas-furnaces, power systems for navigation of sailing boats, silent power supplies on recreational vehicles, cogeneration of electricity and heat, large-scale recovery of high-temperature waste heat from industrial processes such as glass-manufacture, and many others. Military organizations have also taken a keen interest in TPV conversion because of possible strategic advantages that may be realized. Despite its potential advantages and applications, TPV is not yet widely accepted and, so far as the author is aware, only JX Crystals, Inc., is actually manufacturing complete systems.

The most recently archived publications on TPV are to be found in the proceedings of the four 
NREL conferences on the subject. Interested readers are referred to those publications for details.

\section{The generic TPV system}

A generic TPV system consists of a: (i) source of heat (e.g., a flame, radiative isotope, the sun), (ii) radiator, (iii) semiconductor converter, (iv) means of recirculating the sub-bandgap photons to conserve system energy, and (v) power conditioning system. The various options for items (ii), (iii), and (iv), as well as their performance are discussed in this paper. It must be appreciated that each of these processes has an efficiency of less than unity, thus implying that the overall system efficiency must necessarily be relatively modest. In the short-term, a system efficiency of $20 \%$ would be a very ambitious goal. Nearly all work undertaken to date has concerned the optimization of individual components, with relatively little work being devoted to the system as a whole. This rather unbalanced approach has been addressed, to some extent, in recent years but more work on complete systems - and especially the demonstration of systems - must be performed to demonstrate the full potential of TPV.

\section{The semiconductor converter}

Early work on TPV converters focused mainly on silicon and germanium converters (references). However, the quality of these elemental semiconductors was poor. It is the impressive progress in III-V devices that has led to the high performance of modern TPV devices and the consequent resurgence of interest in this field. Potential reductions in cost may be achieved with development of thin-film converters.

Most, but not all, recent device work has concerned the semiconductors GaInAs and GaInAsSb grown by organo-metallic vapor-phase epitaxy (OMVPE) or by molecular-beam epitaxy (MBE). GaInAs is lattice-matched to an InP substrate when the atomic proportions of Ga:In are in the ratio 47:53. However, this composition corresponds to a bandgap of $0.73 \mathrm{eV}$, which is too large for optimum efficiency. Hence, much effort has been devoted to fabricating InGaAs devices with bandgaps of as little as $0.5 \mathrm{eV}$. This material, of course, is lattice-mismatched to the InP substrate, and success in growing it relatively free of damaging defects (caused by strain relaxation) is of major importance to the technology. In addition, considerable effort has been devoted to the characterization of the alloys. The quaternary alloy GaInAsSb can be grown lattice-matched to either GaSb or InAs substrates, although the former is mainly used. The optimum bandgap can be selected (in the range 0.38-0.7 eV) without compromising lattice-matching, and great progress on GaInAsSb devices has been made. At present, at least up to October 1998, there seems to be little to choose between these two rival alloy systems. Despite this progress in two appropriate multi-component alloys, the only 
commercially manufactured TPV system is the Midnight Sun ${ }^{\circledR}$, marketed by JX Crystals, Inc. This uses the binary semiconductor GaSb, with a bandgap of about $0.7 \mathrm{eV}$. Although this is nonideal, GaSb can be grown in large volume and can easily be processed into a device that performs well. The devices are fabricated from wafers of $\mathrm{p}-\mathrm{GaSb}$, with the junctions being formed by diffusion. Arrays of GaSb cells are connected in series and parallel combinations, and system outputs of as high as 600 watts have been recorded.

\section{The radiator}

The radiator may be either broad- or narrowband. If the former is used, then the spectral emittance must be as close to unity as possible, and the material most commonly used has been silicon carbide. This has an emittance of about 0.9 , and it will withstand temperatures up to about 1900 K. Optimization of the bandgap depends, as expected, on the radiator temperature, and there is inevitably a large proportion of the incident photons that are of too low an energy to be absorbed. For the system to have an acceptable efficiency, these must be re-absorbed to the radiator. This aspect will be discussed in the next section. Narrow-band radiators considered to date include ytterbia, erbia, and holmia. These radiate at energies of about 1.1, 0.7, and $0.5 \mathrm{eV}$, respectively. The selective radiation property arises from the electronic structure; valence electrons are screened from mutual interaction, thereby preventing energy bands from forming. Great progress has been made with selective radiators in recent years, and earlier objections of less-than-ideal performance have largely been overcome. Again, at this stage, there seems to be little to choose between the two approaches.

\section{Photon recirculation}

Photon recirculation involves the reflection of the unusable (and possibly deleterious) longwavelength photons back to the radiator to be reabsorbed. The ideal characteristic of this component is near-zero reflectance up to the bandgap of the semiconductor and unity beyond. This may be achieved in at least four different ways, which will be discussed now.

\section{$\underline{\text { Dielectric filters }}$}

A multilayer stack of dielectric films of alternating high and low refractive indexes can be designed to have a specific optical characteristic by appropriate choice of the number and thicknesses of the layers. However, this approach, although demonstrated to work satisfactorily in $R \& D$, may not be feasible for large-volume manufacture.

\section{$\underline{\text { Plasma filters }}$}

A plasma filter is based on a transparent conducting oxide. By choosing the carrier

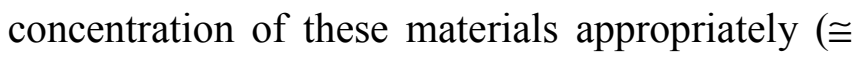
$\left.10^{20} \mathrm{~cm}^{-3}\right)$, the required optical characteristic occurs at the required wavelength $(\cong 2.5 \mu \mathrm{m})$. Operation is based on resonance of the electrons in the film. The performance of the filter is 
adequate but not ideal because, at resonance, the free electrons absorb energy. This prevents the reflectance of the filter from being abrupt, and it reduces the long-wave reflectance to significantly less than $100 \%$. Nevertheless, plasma filters have been used successfully in conjunction with dielectric filters in operational systems.

$\underline{\text { Resonant antennae arrays }}$

An array of features on a dielectric substrate, with dimensions close to the wavelength of the incident radiation $(\cong 2.5 \mu \mathrm{m})$, forms an active optical filter. For slots or crosses in a metallic film, a band-pass filter is formed. For crosses on a dielectric substrate, a band-reject filter is formed. For a TPV converter, the inductive filter is required. High reflectances at both long and short wavelengths have been achieved. This minimizes losses due to both above- and belowbandgap photons. Thermalization of hot carriers and absorption by free electrons are prevented.

\section{$\underline{\text { Back-surface reflectors }}$}

The entire device may be grown on a semiinsulating substrate, in which case, sub-bandgap photons pass through the substrate without significant absorption. This has been achieved with InP substrates and mismatched InGaAs active device layers. With the back surface of the substrate metallized with a specular metal layer, the unabsorbed photons are reflected back to the radiator. This has also been demonstrated satisfactorily.

\section{Systems}

Modeling of TPV systems, using broad-band radiators suggests that efficiencies of $15 \%$ may be achievable in the short-term, but a longer-term effort would be required to reach $20 \%$. There are many issues to consider in the construction of a system, including: non-uniformity of photon flux, photon loss mechanisms, converter temperature, and mismatched performances of individual cells. These factors are difficult to model. Given that existing efficiencies are still significantly less than the above figures, there seems little reason to question modeling data. The relatively low predicted and measured efficiencies are for electrical conversion only. If the waste heat from the burner, e.g., the Midnight Sun ${ }^{\circledR}$ manufactured by JX Crystals, Inc., or from an industrial process, is used, then the efficiency may be claimed to be much higher.

\section{Summary}

The individual components of a TPV system have performed well, but there have not been enough demonstrations of complete systems. At present, there is little to choose between the two main semiconducting alloys and between the selective and broad-band radiators. Back-surface reflectors, however, seem to be the most promising filters, at present. More work on collective optimization of the main components also needs to be done. 